\title{
UCRL-TR-205104
}

\section{Electrochemical Sensors for PEMFC vehicles}

LAWRENCE LIVERMORE NATIONAL LABORATORY

\section{Peter Martin and Robert S. Glass}

\section{April 2004}

\section{Submitted to the Journal of the Electrochemical Society,}

April 2004 
This document was prepared as an account of work sponsored by an agency of the United States Government. Neither the United States Government nor the University of California nor any of their employees, makes any warranty, express or implied, or assumes any legal liability or responsibility for the accuracy, completeness, or usefulness of any information, apparatus, product, or process disclosed, or represents that its use would not infringe privately owned rights. Reference herein to any specific commercial product, process, or service by trade name, trademark, manufacturer, or otherwise, does not necessarily constitute or imply its endorsement, recommendation, or favoring by the United States Government or the University of California. The views and opinions of authors expressed herein do not necessarily state or reflect those of the United States Government or the University of California, and shall not be used for advertising or product endorsement purposes. 


\title{
Electrochemical Sensors for PEMFC vehicles
}

\author{
L. Peter Martin (primary contact) and Robert S. Glass \\ Lawrence Livermore National Laboratory \\ P.O. Box 808, L-353 \\ Livermore, CA 94550 \\ (925) 423-9831, fax: (925) 423-7040, e-mail: martin89@llnl.gov
}

DOE Safety and Codes/Standards Manager:

Neil Rossmeissl

(202) 586-8668, Fax: (202) 586-5860, email: Neil.Rossmeissl@ee.doe.gov

DOE Contractor: Lawrence Livermore National Laboratory

Prime Contract No. W-7405-ENG-48, EE-0502

7000 East Avenue,

Livermore, CA94550

\section{Objectives}

- Develop a hydrogen Safety Sensor operating below $500{ }^{\circ} \mathrm{C}$ with a 1 second or less response time and low sensitivity to humidity and hydrocarbons

- Develop a hydrogen Fuel Loop Sensor for monitoring fuel supply to the fuel cell (supplied either from on-board tank storage or reforming system). Sensor will need to measure hydrogen in the concentration range between 10 to $100 \%$.

- Develop a CO sensor for reformate fuel monitoring(future)

\section{Technical Barriers}

This project addresses the following technical barriers from the 3.4.4.2 section of the Hydrogen, Fuel Cells and Infrastructure Technologies Program Multi Year Research, Development and Demonstration Plan:

- B: Sensors

\section{Approach}

\section{Safety Sensor}

- Utilize proven solid state electrochemical sensor technology and oxygen ion conducting materials similar to automotive exhaust gas oxygen sensors

- Use novel nanocrystalline electrode materials with high electronic conductivity to reduce response time and operating temperature

- Design and build micro-sensor configuration to minimize heater power requirements

\section{Fuel Loop Sensor}

- Develop and characterize an amperometric sensor using a known proton conducting oxide electrolyte

- Correlate 'pumping' current with hydrogen concentration in simulated fuel gas environments

- Reduce operating temperature by applying novel sol-gel fabrication techniques to deposit a thin electrolyte layer 
- Insure electrolyte stability in various fuel gas environments by performing appropriate thermal characterization and electrochemical testing

\section{Accomplishments}

Safety Sensor

- Extended range of $\mathrm{H}_{2}$ concentration measurement up to $10 \%$

- Performed more detailed analysis of operating mechanism

- Evaluated the effects of electrode thickness

- Carefully documented sensor response times

\section{Fuel Loop Sensor}

- Demonstrated a laboratory prototype based on a doped-strontium zirconate

- Zirconate electrolyte was demonstrated to provide sufficient sensitivity and to be stable in $\mathrm{CO}_{2}$

- Sensor response was shown to be linear with logarithm of $\mathrm{H}_{2}$ concentration

- The response time was shown to be approximately 5 seconds from $2 \%$ to $100 \% \mathrm{H}_{2}$

\section{Future directions}

Safety Sensor

- Finalize sensor design

- Locate industrial partner interested in testing / commercialization (Ford and Ballard have agreed to test sensor)

\section{Fuel Loop Sensor}

- Evaluate various materials, processing techniques, and designs

- Fabricate first prototype

- Develop detailed understanding of ageing mechanisms

- Develop integrated sensor

\section{Introduction}

Proton Exchange Membrane Fuel Cells (PEMFCs) are among the most promising clean power system technologies being developed for transportation applications. However, the use of hydrogen and other combustible gases for automotive applications requires new on-board safety sensors and controls to prevent fire and explosion hazards. In addition, fuel cell manufacturers have indicated that they have a strong need for a hydrogen Fuel Loop Sensor. This sensor is needed regardless of whether hydrogen is supplied from onboard storage systems or generated in a reformer. The need for a hydrogen Fuel Loop Sensors is obvious in the case of on-board reforming where a variable mixture of $\mathrm{H}_{2}$, $\mathrm{H}_{2} \mathrm{O}, \mathrm{N}_{2}, \mathrm{CO}, \mathrm{CO}_{2}$, and residual hydrocarbons is generated and supplied to the PEMFC. For on-board storage systems, the sensor is needed because FCVs use exhaust gas recirculation and therefore there could be build up of water, nitrogen, and other diluents in the fuel stream. In either case, a Fuel Loop Sensors is needed in order to protect and to efficiently operate the PEMFCs. 
The purpose of this project is to design, fabricate, and demonstrate solid state electrochemical sensors for various $\mathrm{H}_{2}$ monitoring applications on PEMFC vehicles. The first phase of the project has focused on the development of a hydrogen safety sensor intended to be deployed at critical locations on the vehicle to detect potentially dangerous hydrogen leakage. Currently, that portion of the project is nearing completion, and development of a hydrogen fuel sensor is being initiated. The fuel sensor is intended to monitor the fuel quality (i.e. percent hydrogen) in the gas stream supplied to the PEMFC. Both of these sensors are being developed by applying novel materials to solid state electrochemical sensors.

\section{Approach}

Our approach to the hydrogen safety sensor is based on established solid-state electrochemical sensor technology. The proposed sensor consists of two electrodes on an oxygen ion-conducting electrolyte. One electrode serves as a "reference" and the other as a "sensing" electrode. Note that strict electrochemical nomenclature is not being followed here as the $\mathrm{Pt}$ "reference" electrode does not obtain a poised stable potential to which the "sensing" electrode can be referenced. The electrode materials are selected so that they have different catalytic activities toward the oxidation of hydrogen gas. This causes the electrodes to individually reach a potential that is dictated by electrochemical kinetics. The sensor operates by measuring the potential difference between these electrodes and the hydrogen concentration can be correlated with the magnitude of this potential difference. Similar sensors have been proposed in the past [1], however sensitivity and response speed were insufficient for the proposed safety sensor application. We have proposed that by using a higher conductivity electrode material, response time can be reduced to the point where the sensor becomes suitable for the safety application. For that reason, the current safety sensor uses a metal oxide (indium oxide) doped to promote electronic conductivity. The resultant fast response, along with the sensitivity of the sensor will be shown below.

The hydrogen fuel sensor operates on a very different principal whereby the hydrogen is electrochemically dissociated and pumped through a proton-conducting ceramic membrane. The pumping current (at constant applied voltage) can be correlated to the hydrogen concentration in the test gas. The approach to realizing this sensor will proceed in two parts. The first will be to demonstrate the sensing technology using a known proton conductor with established stability in the reformate environment. However, since these materials tend to be comparatively poor proton conductors, the operating temperature will be required to be fairly high $\left(\sim 600{ }^{\circ} \mathrm{C}\right)$. The second part of the developmental effort will be to explore techniques for reducing the operating temperature including reducing the electrolyte thickness, and attempting to identify alternative proton conductors providing the optimum combination of conductivity and stability for the proposed application. Once identified, this 'optimum' electrolyte will be implemented in the sensor technique demonstrated in the first part of the project. Progress towards these goals will be discussed below. 


\section{$\underline{\text { Results }}$ \\ Safety Sensor}

During FY 03, a integrated safety sensor was demonstrated which had good sensitivity and response time while operating at $440{ }^{\circ} \mathrm{C}$. In the integrated design, the yttriastabilized zirconia (YSZ) electrolyte is deposited onto the surface of an alumina substrate containing an integrated $\mathrm{Pt}$ resistive heater [2]. At $440{ }^{\circ} \mathrm{C}$, the sensor exhibited a baseline near $0 \mathrm{mV}$ in the absence of $\mathrm{H}_{2}$, and a reproducible response of $\sim 225$ or $250 \mathrm{mV}$ to 3300 ppm $(0.33 \%) \mathrm{H}_{2}$ in air containing $10 \%$ and $100 \%$ relative humidity, respectively. The sensor had a response time of approximately one second. Finally, the sensor was shown to have a selectivity coefficient of about 5 for detection of hydrogen over $\mathrm{CH}_{4}$, a potentially significant interfering gas.

During FY04, more extensive testing of non-integrated (non self-heated) sensors was performed in order to evaluate the performance over a wider range of $\mathrm{H}_{2}$ concentrations (up to 10\%). Non-integrated sensors were used in order to facilitate extensive testing of a large number of sensors without consuming the heated substrates, which represent a high value added item. In addition, testing was performed which provided a more extensive analysis of the operating mechanism, evaluation of the effects of the thickness of the tindoped indium oxide sensing electrodes, and careful documentation of sensor response times. These results are discussed in more detail below.

Figure 1 shows the sensor response versus $\mathrm{H}_{2}$ concentration at 450,500 and $550^{\circ} \mathrm{C}$. The sensor response is greater at $500{ }^{\circ} \mathrm{C}$ than at $550{ }^{\circ} \mathrm{C}$ at all $\mathrm{H}_{2}$ concentrations. When the temperature is further reduced to $450^{\circ} \mathrm{C}$, the sensitivity enhancement is smaller and decays with increasing $\mathrm{H}_{2}$ concentration until the data converge with the $500^{\circ} \mathrm{C}$ data. This convergence was also exhibited by other sensors with different ITO thicknesses. This temperature dependence is probably related to either: a) smaller differences in the reaction kinetics between the ITO "sensing" electrode and the platinum "reference" electrode, resulting in a lower potential difference, or b) the inability of the entire system to reach the same quasi-equilibrium steady state as at higher temperature due in general to the reduced reaction kinetics, and in particular to the reduced oxide ion conductivity in the YSZ. For all temperatures, the sensor response in Figure 1 can be described by

$$
E_{m}=C_{1}+C_{2} \ln \left[C\left(O_{2}\right)\right]-C_{3} \ln \left[C\left(H_{2}\right)\right]
$$

where $\mathrm{E}_{\mathrm{m}}$ is the measured response, $\mathrm{C}_{1}, \mathrm{C}_{2}$, and $\mathrm{C}_{3}$ are constants, and $\mathrm{C}\left(\mathrm{O}_{2}\right)$ and $\mathrm{C}\left(\mathrm{H}_{2}\right)$ are the oxygen and hydrogen concentrations, respectively. The dotted lines in the Figure represent the best fit of Eq. (1) to the data at the three temperatures.

Sensor response times were measured at different $\mathrm{H}_{2}$ concentrations. These data are shown in Figure 2, during operation at $500^{\circ} \mathrm{C}$, where the response times were calculated from the baseline to $90 \%$ of full response ( $\mathrm{t}_{90}$ ) and from $10 \%$ to $90 \%$ of the full response $\left(\mathrm{t}_{10-90}\right)$. The latter value is probably somewhat more accurate in that there is a noiselimited error involved in identifying the point at which the sensor response deviates from the baseline. Based on these data, response times decrease with increasing $\mathrm{H}_{2}$ concentration and are less than $1 \mathrm{~s}$ for concentrations greater than $0.03 \%$. This is 
completely acceptable for a hydrogen sensor to be used in safety applications for hydrogen leaks on vehicles.

Figure 3 shows the sensor response to $\mathrm{H}_{2}, \mathrm{H}_{2} \mathrm{O}, \mathrm{CO}_{2}$ and $\mathrm{CH}_{4}$, when operated at $500^{\circ} \mathrm{C}$ in $10 \%$ and $90 \%$ relative humidity. The indicated $\mathrm{CO} 2$ concentrations represent the excess above the ambient air level $(\sim 1 \%)$. These data indicate that the sensor is fairly insensitive to relative humidity in the $10-90 \%$ range., with a change in response of not more than $10 \%$ (in the positive direction) in going from $10 \%$ to $90 \%$. In addition, the sensor response is stable and reproducible over this same humidity range over the duration of the test. It can be seen that the sensor is not responsive to $\mathrm{H}_{2} \mathrm{O}$ or $\mathrm{CO}_{2}$ over the ranges tested. In contrast, the sensor responds to $\mathrm{CH}_{4}$, although with a significantly lower response than to $\mathrm{H}_{2}$ (the sensor is approximately five and three times more sensitive to $\mathrm{H}_{2}$ than to $\mathrm{CH}_{4}$ at $0.1 \%$ and $5 \%$ concentration, respectively ).

\section{Fuel Loop Sensor}

Development of the Hydrogen Fuel Loop sensor has been initiated, and a preliminary prototype sensor has been fabricated from a Sr-zirconate electrolyte with known stability in $\mathrm{H}_{2} \mathrm{O}$ and $\mathrm{CO}_{2}$ gas. Figure 4 shows the pumping current (i.e. the response) of that sensor operated at $600{ }^{\circ} \mathrm{C}$ as a function of $\mathrm{H}_{2}$ concentration. The test gas was composed of the indicated concentration of $\mathrm{H}_{2}$ with $20 \% \mathrm{H}_{2} \mathrm{O}$ and a balance of $\mathrm{N}_{2}$. These data clearly show a linear response to the logarithm of the $\mathrm{H}_{2}$ concentration in the test gas. As shown in the Figure, the cross-sensitivity to $\mathrm{CO}_{2}$ is negligible for concentrations up to $10 \%$ or more. By incorporation of a diffusion limiting porous barrier over one of the electrodes, it should be feasible to force the response of the sensor to be linear with $\mathrm{H}_{2}$ concentration.

\section{Conclusions}

An $\mathrm{H}_{2}$ safety sensor has been demonstrated with high sensitivity, fast response time, and good selectivity to $\mathrm{H}_{2}$ in ambient air. We have elicited interest from industrial collaborators who are interested in testing the sensor in fuel cell systems. For the Hydrogen Fuel Loop Sensor a candidate electrolyte has been identified. Preliminary laboratory prototypes have been fabricated and are being tested. The sensor has been shown to be insensitive to $\mathrm{CO}_{2}$. Ongoing developmental efforts for the Fuel Loop sensor include evaluation of various materials, processing techniques, and designs. In addition, an industrial collaboration will be sought to facilitate the eventual commercialization of an integrated Fuel Loop sensor.

\section{References}

1. G. Lu, N. Miura and N. Yamazoe, "High-temperature hydrogen sensor based on stabilized zirconia and a metal oxide electrode," Sensors and Act., B35-36, (1996) 130135.

2. Supplied by Rick Soltis, Ford Research Center, Dearborn, MI.

\section{FY 2004 Publications/Presentations}

L. P. Martin, Q. Pham, and R. S. Glass, "Electrochemical Hydrogen Sensor for Safety Monitoring," accepted for publication in Solid State Ionics(April 
2004). See also Proceedings of The $14^{\text {th }}$ International Meeting on Solid State

Ionics, Asilomar, CA (June 22-27, 2003).

L. P. Martin and R. S. Glass, "Hydrogen Sensor Based on Yttria-Stabilized Zirconia Electrolyte and Tin-Doped Indium Oxide Sensing Electrode," submitted for publication in The Journal of The Electrochemical Society (April, 2004).

L. Peter Martin and Robert S. Glass, "Electrochemical Sensors for PEMFC Vehicles," presented at The 2004 DOE Hydrogen, Fuel Cells, and Infrastructure Technologies Program Review, Philadelphia, PA (May 27, 2004).

L. P. Martin, A.-Q. Pham, and R. S. Glass, "Hydrogen Sensor Based on Yttria-Stabilized Zirconia Electrolyte and Rh-Promoted ITO Sensing Electrode," presented at The $204^{\text {th }}$ Meeting of The Electrochemical Society, Orlando, FL (October 12-17, 2003).

\section{Acronyms}

$\mathrm{mV}-$ milliVolts

$\mathrm{mA}$ - milliAmps

PEMFC - Polymer electrolyte membrane fuel cell

ppm - parts-per-million (one part-per-million is equivalent to $0.0001 \%$ )

TGA - Thermogravimetric analysis

\section{Figure Captions}

Figure 1: Safety Sensor response versus $\mathrm{H}_{2}$ concentration at 450,500 and $550^{\circ} \mathrm{C}$. The dotted lines show the best fit of Eq. (1) to the data.

Figure 2: Safety Sensor response time as a function of $\mathrm{H}_{2}$ concentration. Response times are measured from the baseline to $90 \%$ of the full response ( $\left.t_{90}\right)$ and from $10 \%$ to $90 \%$ of the full response $\left(\mathrm{t}_{10-90}\right)$.

Figure 3: Safety Sensor response at $500^{\circ} \mathrm{C}$ to $\mathrm{H}_{2}$ in $10 \%(\diamond)$ and $90 \%(\diamond)$ relative humidity (RH). Also shown are the response to $\mathrm{CH}_{4}, \mathrm{CO}_{2}$, and $\mathrm{H}_{2} \mathrm{O}$.

Figure 4: Fuel Loop Sensor response versus $\mathrm{H}_{2}$ concentration at $600{ }^{\circ} \mathrm{C}$. Two tests are shown: 0 and $10 \% \mathrm{CO}_{2}$. In both cases the test gas includes $20 \% \mathrm{H}_{2} \mathrm{O}$ in a balance of $\mathrm{N}_{2}$. The applied bias is $250 \mathrm{mV}$. 


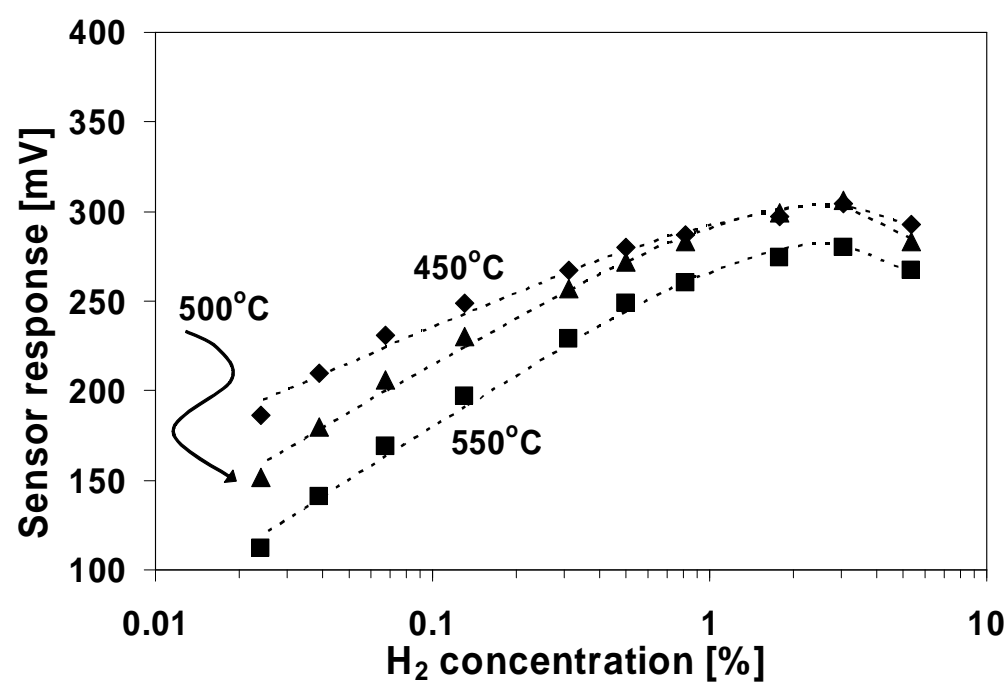

Figure 1: Safety Sensor response versus $\mathrm{H}_{2}$ concentration at 450,500 and $550^{\circ} \mathrm{C}$. The dotted lines show the best fit of Eq. (1) to the data.

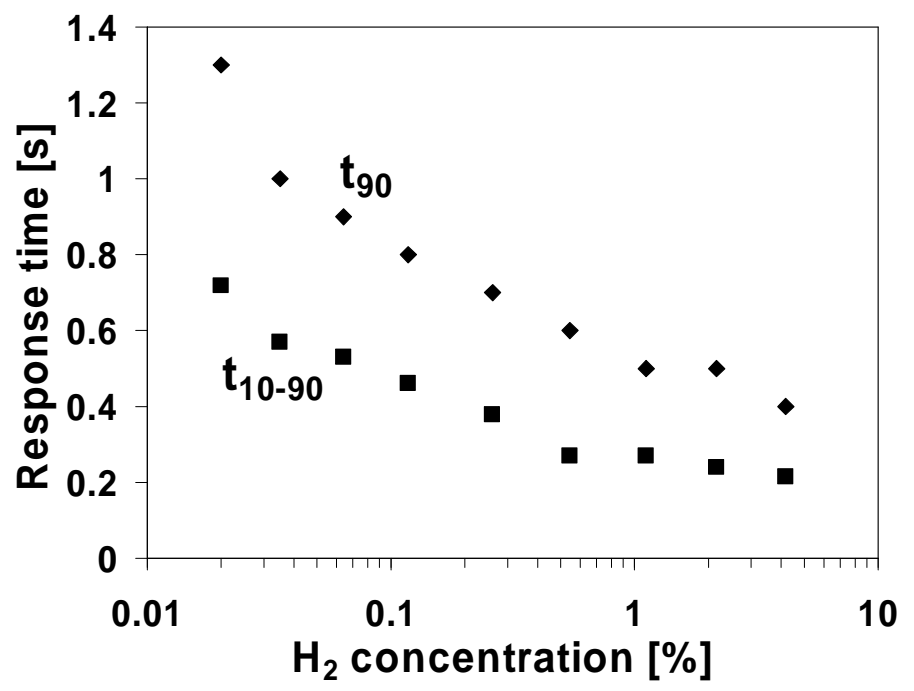

Figure 2: Safety Sensor response time as a function of $\mathrm{H}_{2}$ concentration. Response times are measured from the baseline to $90 \%$ of the full response ( $\left.t_{90}\right)$ and from $10 \%$ to $90 \%$ of the full response $\left(\mathrm{t}_{10-90}\right)$. 


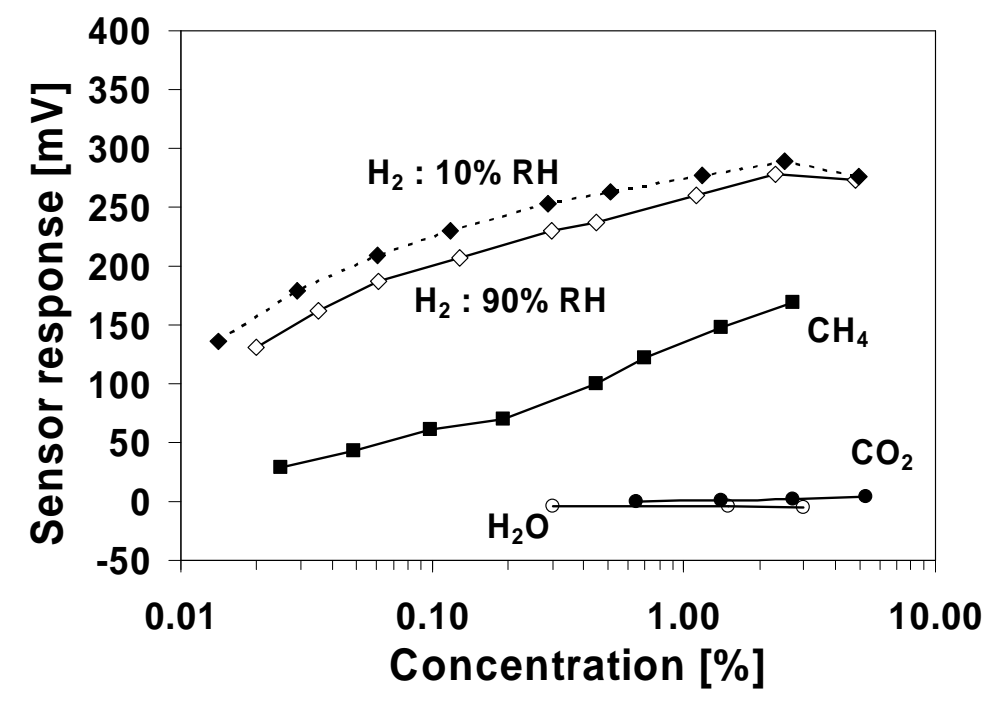

Figure 3: Safety Sensor response at $500^{\circ} \mathrm{C}$ to $\mathrm{H}_{2}$ in $10 \%(\diamond)$ and $90 \%(\diamond)$ relative humidity (RH). Also shown are the response to $\mathrm{CH}_{4}, \mathrm{CO}_{2}$, and $\mathrm{H}_{2} \mathrm{O}$.

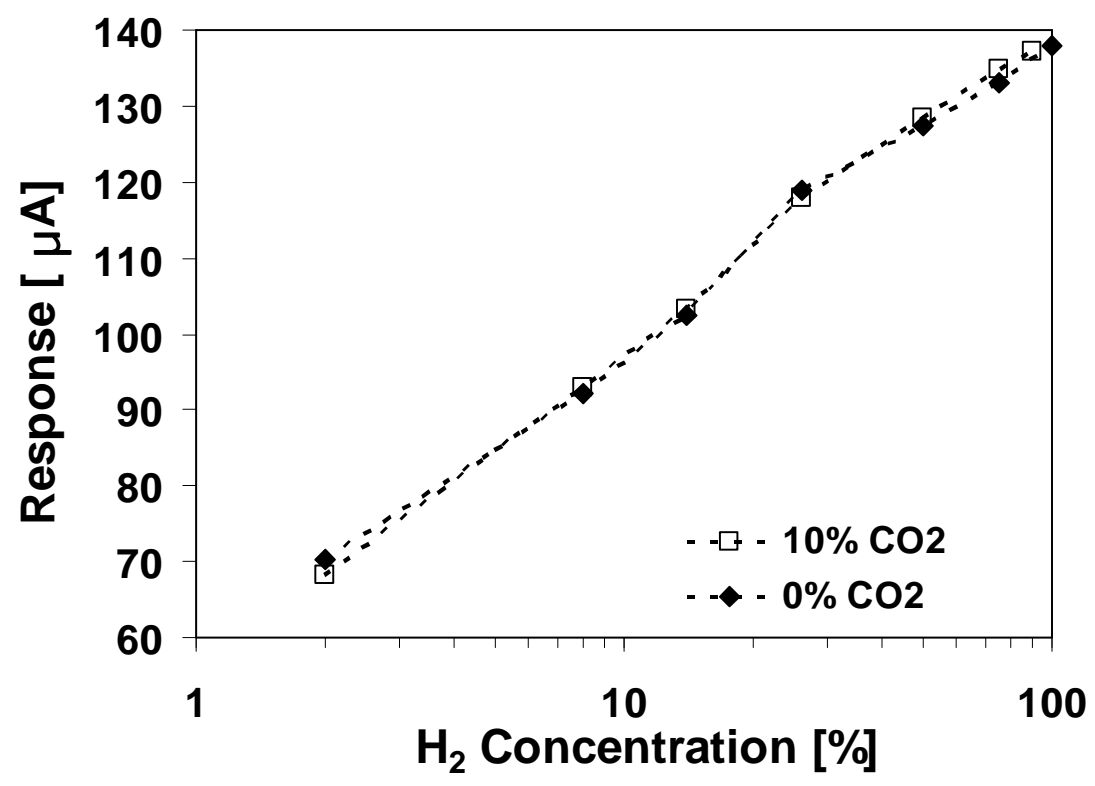

Figure 4: Fuel Loop Sensor response versus $\mathrm{H}_{2}$ concentration at $600{ }^{\circ} \mathrm{C}$. Two tests are shown: 0 and $10 \% \mathrm{CO}_{2}$. In both cases the test gas includes $20 \% \mathrm{H}_{2} \mathrm{O}$ in a balance of $\mathrm{N}_{2}$. The applied bias is $250 \mathrm{mV}$. 